\title{
Analytical Model of Planar Double Split Ring Resonator
}

\author{
Zhurbenko, Vitaliy; Jensen, Thomas; Krozer, Viktor; Meincke, Peter
}

Published in:

Proceedings of the International Microwave \& Optoelectronics Conference

Link to article, DOI:

10.1109/IMOC.2007.4404369

Publication date:

2007

Document Version

Publisher's PDF, also known as Version of record

Link back to DTU Orbit

\section{Citation $(A P A)$ :}

Zhurbenko, V., Jensen, T., Krozer, V., \& Meincke, P. (2007). Analytical Model of Planar Double Split Ring Resonator. In Proceedings of the International Microwave \& Optoelectronics Conference (pp. 753-756). IEEE. https://doi.org/10.1109/IMOC.2007.4404369

\section{General rights}

Copyright and moral rights for the publications made accessible in the public portal are retained by the authors and/or other copyright owners and it is a condition of accessing publications that users recognise and abide by the legal requirements associated with these rights.

- Users may download and print one copy of any publication from the public portal for the purpose of private study or research.

- You may not further distribute the material or use it for any profit-making activity or commercial gain

- You may freely distribute the URL identifying the publication in the public portal 


\title{
Analytical Model of Planar Double Split Ring Resonator
}

\author{
Vitaliy Zhurbenko, Thomas Jensen, Viktor Krozer, Peter Meincke \\ Technical University of Denmark, Ørsted•DTU, ElectroScience, \\ Ørsteds Plads, building 348, 2800 Kgs. Lyngby, Denmark, Phone:+45-45253861, Fax: +45-45931634 \\ E-mail: tje@ oersted.dtu.dk
}

\begin{abstract}
This paper focuses on accurate modelling of microstrip double split ring resonators. The impedance matrix representation for coupled lines is applied for the first time to model the SRR, resulting in excellent model accuracy over a wide frequency range. Phase compensation is implemented to take into account the curved shape of the resonators. The presented results show that the accuracy better than $0.5 \%$ for the first four resonances. Analysis of a periodical structure with frequency selective properties is presented.
\end{abstract}

Index Terms - Split ring resonator, metamaterial, microstrip circuit, coupled lines, impedance matrix.

\section{INTRODUCTION}

$\mathrm{R}$ ecently microstrip filters based on electromagnetic bandgap (EBG) structures and metamaterials have attracted a great deal of interest because of improved characteristics in comparison to traditional filter design [1-3]. In planar filter design the synthesis of metamaterials is successfully done with double split ring resonators, originally proposed by Pendry et al. [4]. The main obstacle for filter design with the SRR technology is the lack of accurate analytical models and the designer usually has to use fullwave electromagnetic simulations in order to obtain a sufficiently accurate prediction of the response. This approach is inefficient because it is extremely time consuming.

Analytical models based on lumped elements where the element values have been extracted from electromagnetic simulations or measurements have been presented [5], but they are restricted to a narrow frequency range around the resonant frequency. The model presented in [6] provides a wideband analysis, but, unfortunately, doesn't take into account the presence of a ground plane in planar structures.

Here it is shown that the response of microstrip double SRR can be accurately predicted using sections of coupled transmission lines. The proposed analytical representation greatly reduces the simulation time with good correlation between model and full-wave electromagnetic simulations. In section II an analytical model based on impedance matrices for coupled lines, transmission lines and microstrip gaps is derived for microstrip double SRR. Section III shows investigations of the models accuracy and section IV provides an example of a stopband structure analysis based on the proposed model.

\section{MODEL FOR MicROSTRIP DOUBLE SRR}

The double SRR structure consists of a pair of concentric rings with splits etched on opposite sides. The double SRR layout and proposed model representation are shown in Fig.1.

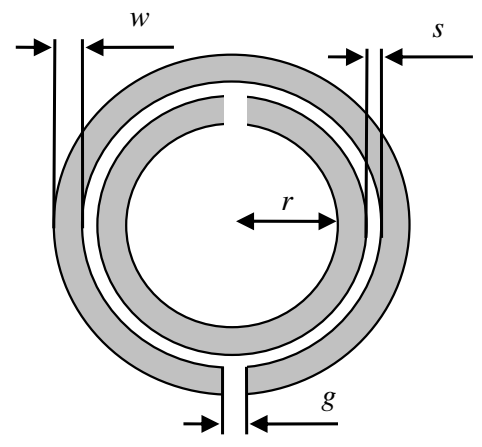

(a)

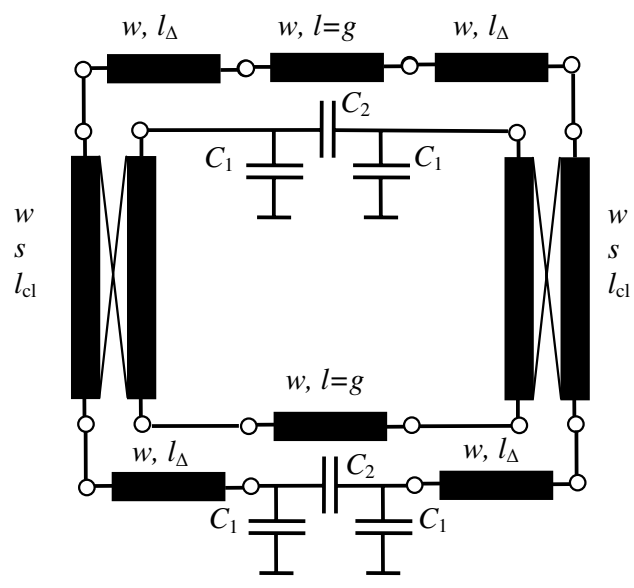

(b)

Fig. 1. Microstrip SRR geometry and corresponding model representation. 
The model is based on two coupled line sections with a length equal to

$$
l_{\mathrm{cl}}=\pi\left(r+\frac{w}{2}\right)-g
$$

However, this length only corresponds to the length of the inner semi-ring.

It is obvious that the lengths of the two resonators are not equal. In most practical cases this difference between the electrical lengths at the first resonant frequency reaches a few tens of degrees and even higher. It is not sufficient to describe a double SRR by just two coupled line sections with a length equal to the average resonators length. To compensate for this difference four transmission lines with a length equal to

$$
4 l_{\Delta}=2\left(\pi\left(r+\frac{3 w}{2}+s\right)-g-l_{\mathrm{cl}}\right)
$$

have to be introduced as shown in Fig. 1(b). Such a phase compensation significantly improves the model accuracy resulting in good agreement between simulated and calculated results, as shown later.

An equivalent circuit for the microstrip gap $g$ of the resonators is a symmetric 2-port $\pi$-network, as shown in Fig. 1(b). The capacitance $C_{2}$ is due to the charge build-up between the two microstrip lines. The capacitance $C_{1}$ is due to the fringing fields at the open circuits. The calculation of values for these capacitors is well described in literature [7-9] and is not considered here.

The transmission line with a length equal to $g$ unites the two semi-rings, which are represented by coupled lines.

The circuit in Fig. 1(b) is transformed to an impedance matrix network with the corresponding matrix representation of the circuit elements. This network is shown in Fig. 2, where $\left[\mathrm{Z}_{\mathrm{CL}}\right]$ stands for the impedance matrix of the coupled lines four-port.

A total of four quantities is required to describe symmetric coupled lines [10]: $Z_{0 o}$ and $Z_{0 e}$, which are, respectively, the characteristic impedances for odd and even modes of propagation; $\gamma_{o}$ and $\gamma_{e}$, the propagation constants of odd and even modes. The elements of the impedance matrix $\left[\mathrm{Z}_{\mathrm{CL}}\right]$ are given by

$$
\begin{gathered}
Z_{11}=Z_{22}=Z_{33}=Z_{44}=-\frac{j}{2}\left(Z_{0 e} \cot \left(\gamma_{e} l_{\mathrm{cl}}\right)+Z_{0 o} \cot \left(\gamma_{o} l_{\mathrm{cl}}\right)\right), \\
Z_{12}=Z_{21}=Z_{34}=Z_{43}=-\frac{j}{2}\left(Z_{0 e} \cot \left(\gamma_{e} l_{\mathrm{cl}}\right)-Z_{0 o} \cot \left(\gamma_{o} l_{\mathrm{cl}}\right)\right), \\
Z_{13}=Z_{31}=Z_{24}=Z_{42}=-\frac{j}{2}\left(Z_{0 e} \csc \left(\gamma_{e} l_{\mathrm{cl}}\right)-Z_{0 o} \csc \left(\gamma_{o} l_{\mathrm{cl}}\right)\right),
\end{gathered}
$$

$Z_{14}=Z_{41}=Z_{23}=Z_{32}=-\frac{j}{2}\left(Z_{0 e} \csc \left(\gamma_{e} l_{\mathrm{cl}}\right)+Z_{0 o} \csc \left(\gamma_{o} l_{\mathrm{cl}}\right)\right)$,

where $l_{\mathrm{cl}}$ is the length of the coupled line section, as it is shown in Fig. 1(b).

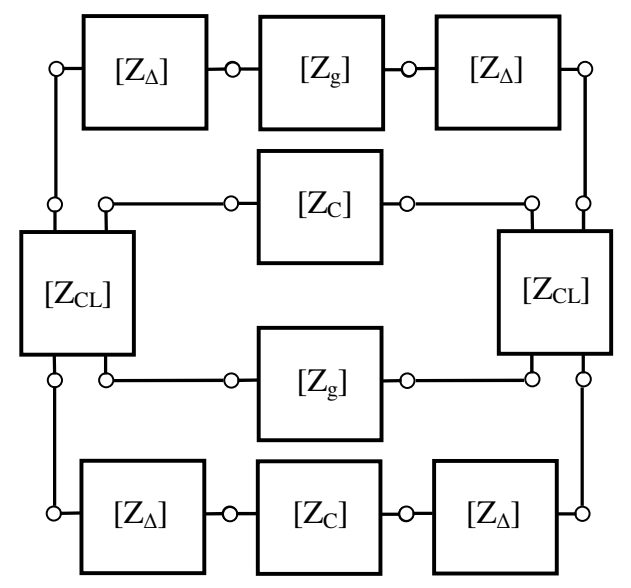

Fig. 2. Double SRR model based on an impedance matrix representation.

The matrices for the transmission lines of the model (Fig. 1.(b)) are given to be

$$
\left[Z_{g}\right]=\left[\begin{array}{ll}
Z_{0} \operatorname{coth}(\gamma g) & Z_{0} \operatorname{csch}(\gamma g) \\
Z_{0} \operatorname{csch}(\gamma g) & Z_{0} \operatorname{coth}(\gamma g)
\end{array}\right],
$$

and

$$
\left[Z_{\Delta}\right]=\left[\begin{array}{ll}
Z_{0} \operatorname{coth}\left(\gamma l_{\Delta}\right) & Z_{0} \operatorname{csch}\left(\gamma l_{\Delta}\right) \\
Z_{0} \operatorname{csch}\left(\gamma l_{\Delta}\right) & Z_{0} \operatorname{coth}\left(\gamma l_{\Delta}\right)
\end{array}\right]
$$

Here $Z_{0}$ is the characteristic impedance of the microstrip line, and $\gamma$ its propagation constant.

The calculation of electrical parameters for the microstrip lines and coupled lines can be performed using empirical expressions [11] or any free or commercially available software transmission line calculators.

The impedance matrix for the microstrip gap is

$$
\left[Z_{C}\right]=\left[\begin{array}{cc}
\frac{\mathrm{C}_{1}+\mathrm{C}_{2}}{j \omega \mathrm{C}_{1}\left(2 \mathrm{C}_{2}+\mathrm{C}_{1}\right)} & \frac{\mathrm{C}_{2}}{j \omega \mathrm{C}_{1}\left(2 \mathrm{C}_{2}+\mathrm{C}_{1}\right)} \\
\frac{\mathrm{C}_{2}}{j \omega \mathrm{C}_{1}\left(2 \mathrm{C}_{2}+\mathrm{C}_{1}\right)} & \frac{\mathrm{C}_{1}+\mathrm{C}_{2}}{j \omega \mathrm{C}_{1}\left(2 \mathrm{C}_{2}+\mathrm{C}_{1}\right)}
\end{array}\right] .
$$

Using this model representation the response of the resonator can be predicted in a wide frequency range. 


\section{Model Validation}

To estimate the proposed model accuracy the calculated response of the microstrip double SRR is compared to fullwave simulations using method of moments (MoM). The considered configuration is based on a substrate with a dielectric constant $\varepsilon_{\mathrm{r}}=3.38$ and thickness $\mathrm{h}=0.8 \mathrm{~mm}$. The SRR parameters and the relative difference between calculated and simulated resonant frequency $\delta f_{i}$ are given in Table 1 for the first four resonant frequencies, respectively.

TABLE 1

RESONATOR PARAMETERS AND ESTIMATION OF MODEL ACCURACY

\begin{tabular}{l|c|c|c|c|c|c|c|c}
\hline \hline Parameter & $\begin{array}{c}r \\
(\mathrm{~mm})\end{array}$ & $\begin{array}{c}w \\
(\mathrm{~mm})\end{array}$ & $\begin{array}{c}s \\
(\mathrm{~mm})\end{array}$ & $\begin{array}{c}g \\
(\mathrm{~mm})\end{array}$ & $\begin{array}{c}\delta f_{1} \\
(\%)\end{array}$ & $\begin{array}{c}\delta f_{2} \\
(\%)\end{array}$ & $\begin{array}{c}\delta f_{3} \\
(\%)\end{array}$ & $\begin{array}{c}\delta f_{4} \\
(\%)\end{array}$ \\
\hline Value & 12.7 & 0.2 & 0.17 & 0.17 & 0.02 & 0.06 & 0.17 & 0.3 \\
\hline \hline
\end{tabular}

The SRR structure exhibits resonant frequencies within a wide range of frequencies. The first resonant frequency is predicted with an accuracy better than $0.02 \%$ and all resonant frequencies are predicted with an accuracy better than $0.5 \%$. The main contribution to the inaccuracy originates from the electrical model parameter relations for coupled lines, transmission lines, and capacitances $\mathrm{C}_{1}, \mathrm{C}_{2}$.

As expected, the resonant frequency calculation inaccuracy increases for higher order resonances, but is significantly less than $1 \%$. Such an accuracy is deemed sufficient for filter design.

\section{Modelling OF StOpBAnd STRUCtURE}

A double SRR is often used as a unit cell in electromagnetic metamaterials. Such materials are formed from repeated unit cells containing scattering elements. Therefore it is interesting to investigate the reliability of the proposed model considering a structure, which contains a number of double SRRs.

Double SRRs are a well known alternative to EBG structures for the rejection of frequency bands in planar transmission lines. A behaviour similar to EBG structures can be achieved by implementing periodical loading of a planar transmission line with double SRRs.

The microstrip double SRR was implemented to form a stopband structure in a microstrip transmission line. Twenty double SRRs with varying resonance frequency are coupled to a transmission line using short stubs. In such a type of transmission line the signal propagation is inhibited in a certain frequency band. This property is used to build a microstrip stopband structure in a form as shown in Fig. 3.

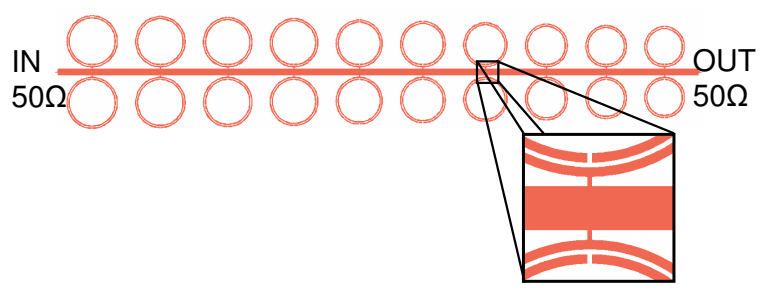

Fig. 3. Periodically loaded $50 \Omega$ microstrip transmission line.

The considered structure is electrically large resulting in complicated, time consuming full-wave analysis. The varying resonant frequency of individual cells prohibits the reuse of full-wave single cell simulation results for the overall structure.

The model developed here is used to design the structure with a frequency stopband around $2 \mathrm{GHz}$, using a substrate with $\varepsilon_{\mathrm{r}}=3.38$ and height $\mathrm{h}=0.8 \mathrm{~mm}$. The transmission line width is equal to $1.86 \mathrm{~mm}$. The connecting stubs length and width are $0.4 \mathrm{~mm}$ and $0.2 \mathrm{~mm}$, respectively. The distance between two adjacent double SRRs is equal to $5 \mathrm{~mm}$. The dimensions for the SRR, as illustrated in Fig. 1(a), are $s=g=0.2 \mathrm{~mm}, w=0.4 \mathrm{~mm}$. The radiuses $r$ of the resonators are $6.55 \mathrm{~mm}, 6.45 \mathrm{~mm}, 6.3 \mathrm{~mm}, 6.15 \mathrm{~mm}, 5.95 \mathrm{~mm}, 5.75 \mathrm{~mm}$, $5.55 \mathrm{~mm}, 5.35 \mathrm{~mm}, 5.15 \mathrm{~mm}$, and $5.00 \mathrm{~mm}$.

The calculated response of the microstrip SRR is compared to MoM simulations. The microstrip lines metal is assumed to be lossless with zero thickness to improve MoM computational efficiency.

The calculated and simulated responses are shown in Fig. 4. It can be seen from the presented results that the agreement between calculated and simulated is very good at lower frequencies and the stopband is slightly moved towards lower frequencies (Fig. 4(a)). Discrepancy between calculated and simulated transmission and reflection magnitudes increases in the high frequency region. The simulated $S_{11}$ bandwidth is narrower, than predicted by the model, as can be seen in Fig. 4(b)

The discrepancy may be attributed to the parasitic interactions between the SRRs and the transmission line, which are not considered in the model. This interaction may cause the excitation of undesirable modes in the SRRs. Although the simulation and modelling results agree reasonably well, more work is needed to include mutual coupling affects and parasitic mode excitation in SRRs. 


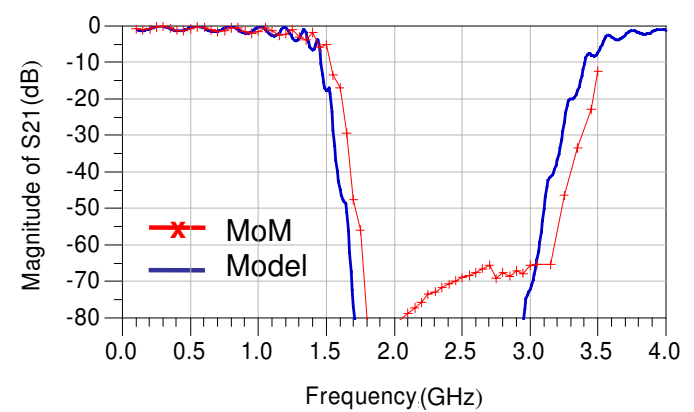

(a)

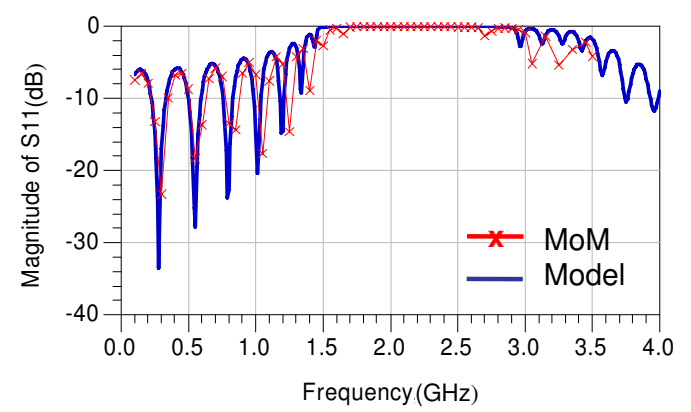

(b)

Fig. 4: Calculated and simulated responses of the structure shown in Fig. 3.

\section{CONCLUSION}

In this work, an analytical model for the microstrip double SRR has been developed based on the impedance matrix representations of coupled lines, transmission lines and microstrip gaps.

The developed model has been validated with MoM simulations. The presented results demonstrate an accurate prediction of the first four resonant frequencies of an SRR with a relative error below $0.5 \%$. The proposed model is reliable in a wide frequency range and provides prediction of higher order resonances, which has not been demonstrated yet with circuit based models.

The proposed analytical model makes it simple and effective to analyze microstrip double SRR structures and electrically large circuits based on it.

As an example the developed model has been used for effective design and analysis of a microstrip stopband structure based on a number of double SRRs. The predicted transmission and reflection performance of the structure compares well with full-wave simulations.

The developed model is intended to be used in a design of compact and high performance components for a microwave camera.

\section{ACKNOWLEDGEMENT}

The authors wish to acknowledge the partial financial support of the Danish Ministry of Research and Education.

\section{REFERENCES}

[1] J. García-García, et al., "Miniaturized Microstrip and CPW Filters Using Coupled Metamaterial Resonators," IEEE Transactions on Microwave Theory and Techniques, vol.54, no. 6, pp. 2628-2634, June 2006.

[2] A. Garcia-Lamperez, M. Salazar-Palma, "Dual Band Filter with Split-Ring Resonators," IEEE MTT-S International Microwave Symposium Digest, pp. 519-522, 2006.

[3] J. García-García, et al., "Microwave Filters with Improved Stopband Based on Sub-Wavelength Resonators," IEEE Transactions on Microwave Theory and Techniques, vol.53, no. 6, pp. 1997-2006, June 2005.

[4] Pendry, J. B., A. J. Holden, D. J. Robbins, and W. J. Stewart, "Magnetism from conductors and enhanced nonlinear phenomena," IEEE Transactions on Microwave Theory and Techniques, vol.47, pp. 2075-2084, 1999.

[5] J. D. Baena, et al., "Equivalent-Circuit Models for Split-Ring Resonators and Complementary Split-Ring Resonators Coupled to planar Transmission Lines," Transactions on Microwave Theory and Techniques, vol. 53, no. 4, April 2005.

[6] M. Shamonin, E. Shamonina, V. Kalinin, and L. Solymar, "Resonant Frequencies of A Split-Ring Resonator: Analytical Solutions and Numerical Simulations," Microwave and Optical Technology Letters, Vol. 44, No. 2, pp. 133-136, January 20 2005.

[7] M. Kirschning, R. H. Jansen, N. H. L. Koster, "Measurement And Computer-Aided Modelling Of Microstrip Discontinuities By An Improved Resonator Method," IEEE MTT-S International Microwave Symposium Digest, pp. 495-497, 1983.

[8] E. Hammerstad, "Computer-Aided Design Of Microstrip Couplers with Accurate Discontinuity Models," IEEE MTT-S International Microwave Symposium Digest, pp. 54-56, 1981.

[9] N. H. L. Koster, R. H. Jansen, "The Equivalent Circuit of the Asymmetrical Series Gap in Microstrip and Suspended Substrate Lines," Transactions on Microwave Theory and Techniques, vol. MTT-30, no. 8, August 1982.

[10] G. I. Zysman, A. K. Johnson, "Coupled Transmission Line Networks in Inhomogeneous Dielectric Medium" Transactions on Microwave Theory and Techniques, vol. MTT-17, no. 10, October 1969.

[11] R. Mongia, I. Bahl, P. Bhartia, RF and Microwave Coupled Line Circuits. Norwood: Artech House microwave library, 1999 